\title{
Intercomparison of $\mathrm{O}_{3}$ profiles observed by SCIAMACHY and ground based microwave instruments
}

\author{
M. Palm ${ }^{1}$, C. v. Savigny ${ }^{1}$, T. Warneke ${ }^{1}$, V. Velazco ${ }^{1}$, J. Notholt ${ }^{1}$, K. Künzi ${ }^{1}$, J. Burrows ${ }^{1}$, and O. Schrems ${ }^{2}$ \\ ${ }^{1}$ Institute of Environmental Physics, University of Bremen, PO Box 330440, 28334 Bremen, Germany \\ ${ }^{2}$ Alfred Wegener Institute for Polar and Marine Research, PO Box 120169, 27515 Bremerhaven, Germany
}

Received: 19 April 2004 - Published in Atmos. Chem. Phys. Discuss.: 18 February 2005

Revised: 13 June 2005 - Accepted: 6 July 2005 - Published: 9 August 2005

\begin{abstract}
Ozone profiles retrieved from limb scattering measurements of the SCIAMACHY instrument based on the satellite ENVISAT are compared to ground-based low altitude resolution remote sensors. All profiles are retrieved using optimal estimation. Following the work of Rodgers and Connor (2003) the retrievals of the ground-based instruments are simulated using the SCIAMACHY retrieval. The SCIAMACHY results and the results of the ground-based microwave radiometer in Bremen and Ny Ålesund agree within the expected covariance of the intercomparison.
\end{abstract}

\section{Introduction}

The ozone profile is of interest because ozone is one of the most important trace gases in the atmosphere. Ozone is a greenhouse gas and provides shielding from UV radiation. Following the discovery of the ozone hole (Farman et al., 1985) a large effort has been put into understanding the reason for it and to establish a network for monitoring the further development of the ozone layer. Although the emission of human made chemicals (CFCs) has been curbed, the rise in the water vapor content of and the decrease of the temperature in the stratosphere still give reasons of concern about the ozone layer (e.g. Rex et al., 2004).

Remote sounding instruments are used to monitor various atmospheric properties like trace gases from ground or satellite. In the upper stratosphere and above very few if any insitu measurements are available. All remote sounders are indirect instruments in the sense that they measure a more or less complicated function of the quantity of interest (Rodgers and Connor, 2003). In order to understand and interpret the data taken it is necessary to understand the relationship between the true atmospheric state and the quantity measured.

Correspondence to: M. Palm

(mathias@iup.physik.uni-bremen.de)
It is also necessary to validate and compare remote sounders on a continuous basis in order to enhance the quality of the measurements and to assess the stability of the combination instrument/retrieval (Rodgers and Connor, 2003).

\section{The instruments}

\section{$2.1 \mathrm{O}_{3}$ profiles from SCIAMACHY on Envisat}

SCIAMACHY, the Scanning Imaging Absorption spectrometer for Atmospheric CHartographY (Bovensmann et al., 1999) is a novel satellite-borne scientific instrument capable of performing spectroscopic measurements of the chemical composition of the Earth's atmosphere in three different observation geometries: nadir, solar/lunar occultation and limb scattering. SCIAMACHY covers the spectral range from $220 \mathrm{~nm}$ to $2380 \mathrm{~nm}$ with a spectral resolution varying from $0.2 \mathrm{~nm}$ to $1.5 \mathrm{~nm}$ depending on wavelength. In limb scattering geometry the instrument line of sight follows a slant path tangentially through the atmosphere. Detected are solar photons that are both (a) scattered along the line of sight into the instrument's field of view, and (b) transmitted from the scattering point to the instrument. The geometrical field of view of SCIAMACHY in limb scattering mode is about $2.8 \mathrm{~km}$ vertically and $110 \mathrm{~km}$ horizontally. The Earth's limb is viewed in flight direction and scanned from tangent heights of about $0 \mathrm{~km}$ up to $100 \mathrm{~km}$ in steps of $3.3 \mathrm{~km}$. Furthermore, at every tangent height step an azimuthal (horizontal) scan is performed covering about $960 \mathrm{~km}$ at the tangent point. Therefore the limb measurement mode amounts to an averaging over about $1000 \mathrm{~km}$ perpendicular to the orbit track. Along the flight track, the averaging occurs over a distance of about $400 \mathrm{~km}$.

The stratospheric $\mathrm{O}_{3}$ profiles used here are derived from SCIAMACHY limb scattering measurements in the Chappuis-bands of $\mathrm{O}_{3}$. The retrieval algorithm employed

(C) 2005 Author(s). This work is licensed under a Creative Commons License. 


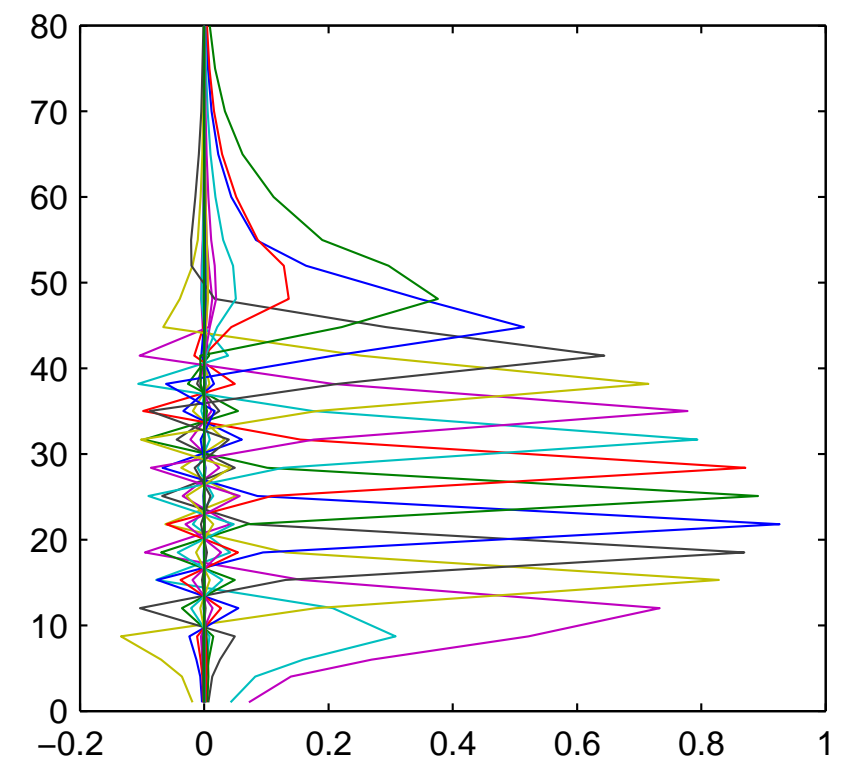

Fig. 1. An example of a set of averaging kernels of the inversion of SCIAMACHY limb spectra.

is similar to the one described in Flittner et al. (2000) and McPeters et al. (2000), and has also been used for operational data processing of limb scattering observations performed with the Optical Spectrograph and InfraRed Imager System (OSIRIS) (von Savigny et al., 2003) on the Swedishled Odin satellite. The retrieval exploits the differential structure of the $\mathrm{O}_{3}$ cross section between the center $(600 \mathrm{~nm})$ and the wings $(525 \mathrm{~nm}$ and $675 \mathrm{~nm})$ of the Chappuis absorption bands of $\mathrm{O}_{3}$. A linearized version of optimal estimation (OE) is used together with the radiative transfer model SCIARAYS (Kaiser et al., 2003) to iteratively retrieve stratospheric $\mathrm{O}_{3}$ concentration profiles. The altitude range from about $15 \mathrm{~km}$ up to $40 \mathrm{~km}$ can be covered with this technique (see Fig. 1 for a set of averaging kernels).

\subsection{The millimeter-wave radiometers BreRAM and RAM}

The millimeter-wave radiometers RAM (Radiometer for Atmospheric Measurements at Ny Ålesund, $78^{\circ} \mathrm{N}, 11^{\circ} \mathrm{E}$ ) and BreRAM (Bremen Radiometer for Atmospheric Measurements at Bremen, $53^{\circ} \mathrm{N}, 8^{\circ} \mathrm{E}$ ) are very similar. Unless specifically noted the following description applies to both.

The instruments are heterodyne millimeter-wave radiometers tuned to frequency of $\mathrm{O}_{3}$ lines at $142 \mathrm{GHz}(\mathrm{RAM})$ and $110.836 \mathrm{GHz}$ (BreRAM). Both instruments are operated in total power mode. In order to resolve the spectra the instruments AOS spectrometers with a bandwidth of about $1 \mathrm{GHz}$ and an effective resolution of $1.3 \mathrm{MHz}$ are used. The receiver noise temperature is about $3000 \mathrm{~K}$. This enables both instruments to measure spectra of the $\mathrm{O}_{3}$ line every half hour. Using a special scheme (Wohltmann, 2002) the integration time can be prolonged up to a day in order to enhance signal-to-

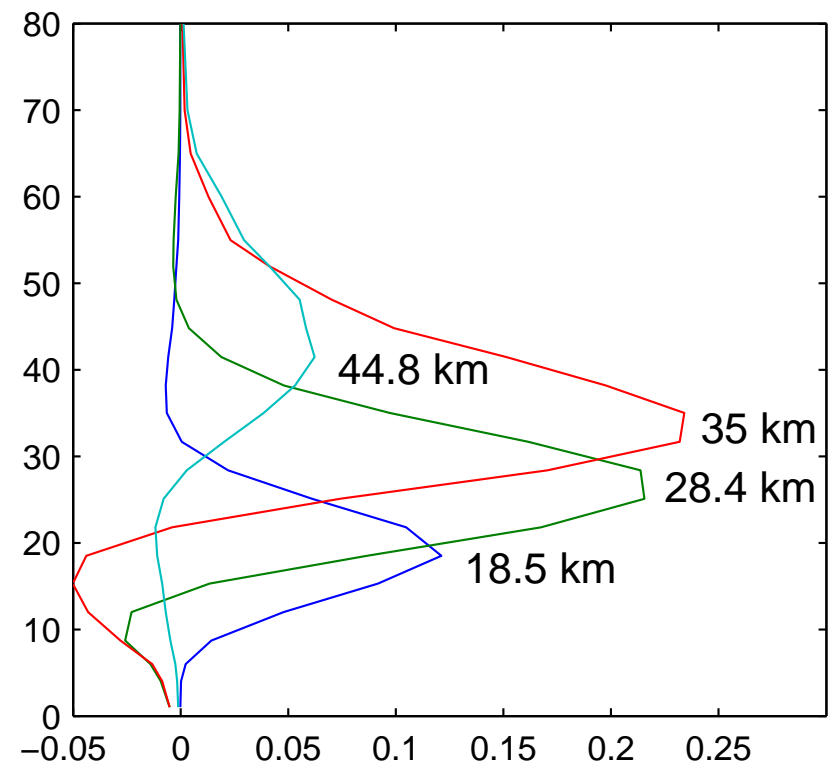

Fig. 2. An example of a set of averaging kernels for the inversion of a RAM-spectrum. Both, BreRAM and RAM are very similar and use the same retrieval routines. The avaraging kernels of a BreRAM retrieval are similar.

noise ratio. Millimeter-wave radiometers are insensitive to meteorological conditions and clouds and do not depend on sun light. Therefore, they provide the most complete time series of the ozone profile.

The $\mathrm{O}_{3}$ profile information is retrieved from the spectra using Optimal Estimation Methods (see Sect. 3 and Rodgers, 2000). Information about the vertical ozone distribution between $15 \mathrm{~km}$ and $55 \mathrm{~km}$ with an altitude resolution of $15 \mathrm{~km}$ at its best can be obtained (see Fig. 2 for examples of averaging kernels).

The RAM measurements at Ny Ålesund are routinely compared to sonde measurements taken at $\mathrm{Ny}$ Ålesund. Hence the RAM is validated up to $25 \mathrm{~km}$. Comparisons to LIDAR and satellite measurements have been undertaken (Langer, 1999) with good results:

- Intercomparison with MLS profiles (20-50 km): RAM underestimates $\mathrm{O}_{3}$-vmr. The deviation is smaller than $10 \%$.

- Intercomparison with sonde profiles (18-24 km): RAM overestimates below $20 \mathrm{~km}$ and underestimates $\mathrm{O}_{3}$-vmr above. Deviation smaller than $10 \%$.

- Intercomparison with LIDAR (16-34 km): RAM overestimates the $\mathrm{O}_{3}$-profile below $20 \mathrm{~km}$ and above $30 \mathrm{~km}$. The $\mathrm{O}_{3}$-profile is underestimated in between. The maximum deviation is $11 \%$. 


\section{The Optimal Estimation Retrieval}

For a detailed discussion of the Optimal Estimation Retrieval (OE) see Rodgers (2000). In this work a brief overview will be given and certain aspects crucial to the understanding of the comparison are discussed. If not noted otherwise the following is based on Rodgers (2000) and Rodgers and Connor (2003).

The retrieval of information about the vertical ozone distribution is mathematically an inverse problem. The relation between a given distribution of ozone in the atmosphere and a spectrum measured on the ground or in space is provided by the forward model $\boldsymbol{F}$. Let $\boldsymbol{x}$ be a given ozone distribution and $\boldsymbol{y}$ a spectrum. A Gaussian distributed error $\boldsymbol{\epsilon}$ with covariance $\mathbf{S}_{\epsilon}$ will be assumed on the spectrum. Hence $\boldsymbol{y}$ is obtained by

$\boldsymbol{y}=\boldsymbol{F}(\boldsymbol{x})+\boldsymbol{\epsilon}=\boldsymbol{F}\left(\boldsymbol{x}_{0}\right)+\frac{\partial \boldsymbol{F}}{\partial \boldsymbol{x}}\left(\boldsymbol{x}-\boldsymbol{x}_{0}\right)+O\left(\boldsymbol{x}^{2}\right)+\boldsymbol{\epsilon}$

which is called the forward problem with the weighting function matrix $\mathbf{K}=\frac{\partial \boldsymbol{F}}{\partial \boldsymbol{x}}$. Using Bayes' law the following relationship for the inverse model (for the detailed discussion please see Rodgers, 2000) is found. Let $\boldsymbol{x}_{a}$ be the a priori profile of $\mathrm{O}_{3}$ and $\mathbf{S}_{a}$ the covariance matrix of $\boldsymbol{x}_{a}$. Let $P(\boldsymbol{x} \mid \boldsymbol{y})$ denote the probability of getting an ozone distribution $\boldsymbol{x}$ given a spectrum $\boldsymbol{y}$. The probability distribution $P(\boldsymbol{x} \mid \boldsymbol{y})$ can be written as:

$$
\begin{array}{r}
P(\boldsymbol{x} \mid \boldsymbol{y})=\exp \left(-(\boldsymbol{F}(\boldsymbol{x})-\boldsymbol{y})^{T} \mathbf{S}_{\epsilon}(\boldsymbol{F}(\boldsymbol{x})-\boldsymbol{y})\right) \\
\times \exp \left(-\left(\boldsymbol{x}_{a}-\boldsymbol{x}\right)^{T} \mathbf{S}_{a}\left(\boldsymbol{x}_{a}-\boldsymbol{x}\right)\right) .
\end{array}
$$

In OE the solution, the optimal profile $\hat{\boldsymbol{x}}$, is found by

$\hat{\boldsymbol{x}}=\boldsymbol{x}_{a}+\mathbf{S}_{a} \mathbf{K}^{T}\left(\mathbf{K S}_{a} \mathbf{K}^{T}+\mathbf{S}_{\epsilon}\right)^{-1}\left(\boldsymbol{y}-\mathbf{K} \boldsymbol{x}_{a}\right)$.

In the case of a weakly non-linear forward model the solution can be found by an iterative algorithm like the LevenbergMarquardt-Algorithm. By defining

$\mathbf{D}=\mathbf{S}_{a} \mathbf{K}^{T}\left(\mathbf{K} \mathbf{S}_{a} \mathbf{K}^{T}+\mathbf{S}_{\epsilon}\right)^{-1}$

Eq. (3) can be written as

$\hat{\boldsymbol{x}}=\boldsymbol{x}_{a}+\mathbf{D}\left(\boldsymbol{y}-\mathbf{K} \boldsymbol{x}_{a}\right)$

and noting that $\boldsymbol{y}=\mathbf{K} \boldsymbol{x}_{\text {True }}$ (the error $\boldsymbol{\epsilon}$ has been omitted), the so called instrument model is

$\hat{\boldsymbol{x}}=\boldsymbol{x}_{a}+\mathbf{D}\left(\mathbf{K} \boldsymbol{x}_{\text {True }}-\mathbf{K} \boldsymbol{x}_{a}\right)=\boldsymbol{x}_{a}+\mathbf{A}\left(\boldsymbol{x}_{\text {True }}-\boldsymbol{x}_{a}\right)$.

Equation (6) relates the unknown true profile $\boldsymbol{x}_{\text {True }}$ to the profile retrieved. The matrix $\mathbf{A}$ is called the resolution kernel matrix and can also be written by

$\mathbf{A}=\frac{\partial \hat{\boldsymbol{x}}}{\partial \boldsymbol{x}_{\text {True }}}$

The resolution kernel matrix A contains information about the sensitivity of the instrument/retrieval to changes in the true profile.

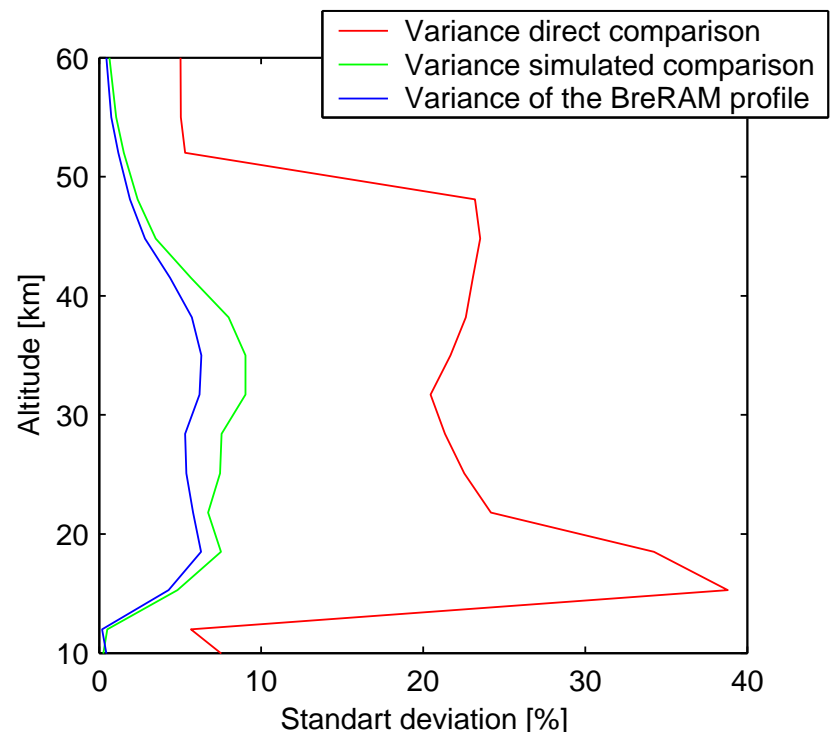

Fig. 3. Expected standard deviations of the direct intercomparison of the BreRAM-SCIAMACHY profiles, the intercomparison of the BreRAM profile with a simulated profile (using the SCIAMACHY profile as $\boldsymbol{x}_{2}$ (Eq. 10). For comparison the expected standard deviation of the BreRAM profile has been plotted. The results are comparable for all ground-based instruments considered in this work.

\subsection{Intercomparison of indirect measurements}

Assume two retrievals 1 and 2 with respect to the a priori $\boldsymbol{x}_{a}$ and $\boldsymbol{x}_{c}$, respectively. The direct difference $\boldsymbol{\delta}_{x}$ of two profiles $\hat{\boldsymbol{x}}_{1}$ and $\hat{\boldsymbol{x}}_{2}$ is

$$
\begin{aligned}
\boldsymbol{\delta}_{x}=\hat{\boldsymbol{x}}_{1}-\hat{\boldsymbol{x}}_{2} & =\boldsymbol{x}_{a}+\mathbf{A}_{1}\left(\boldsymbol{x}_{\text {True }}-\boldsymbol{x}_{a}\right) \\
& -\left(\boldsymbol{x}_{c}+\mathbf{A}_{2}\left(\boldsymbol{x}_{\text {True }}-\boldsymbol{x}_{c}\right)\right)+\boldsymbol{\epsilon}_{1}-\boldsymbol{\epsilon}_{2} \\
& =\left(\mathbf{A}_{1}-\mathbf{A}_{2}\right)\left(\boldsymbol{x}_{\text {True }}-\boldsymbol{x}_{c}\right) \\
& -\left(\mathbf{A}_{1}-\mathbf{I}\right)\left(\boldsymbol{x}_{a}-\boldsymbol{x}_{c}\right)+\boldsymbol{\epsilon}_{1}-\boldsymbol{\epsilon}_{2} .
\end{aligned}
$$

The term $(\mathbf{I}-\mathbf{A})\left(\boldsymbol{x}_{a}-\boldsymbol{x}_{c}\right)$ contains the difference of the a priori profiles of the retrievals. For simplicity, all profiles have been transformed to be with respect to the a priori profile $\boldsymbol{x}_{c}$. This has been done by adding the term $\left(\mathbf{A}_{1}-\mathbf{I}\right)\left(\boldsymbol{x}_{a}-\boldsymbol{x}_{c}\right)$ to the retrieved profile in question. Let $\mathbf{S}_{x_{1}}, \mathbf{S}_{x_{2}}$ be the error covariances of retrieval 1 and 2 , respectively. The expected error covariance $\mathbf{S}_{\delta}$ of the difference of the profiles (Eq. 8) is

$\mathbf{S}_{\delta}=\left(\mathbf{A}_{1}-\mathbf{A}_{2}\right) \mathbf{S}_{c}\left(\mathbf{A}_{1}-\mathbf{A}_{2}\right)^{T}+\mathbf{S}_{x_{1}}+\mathbf{S}_{x_{2}}$.

The expected variance of the profile difference may be quite large (Fig. 3 for an example). Following Rodgers and Connor (2003) another comparison method, retrieval simulation, leads to much smaller expected variances in the profile differences. 


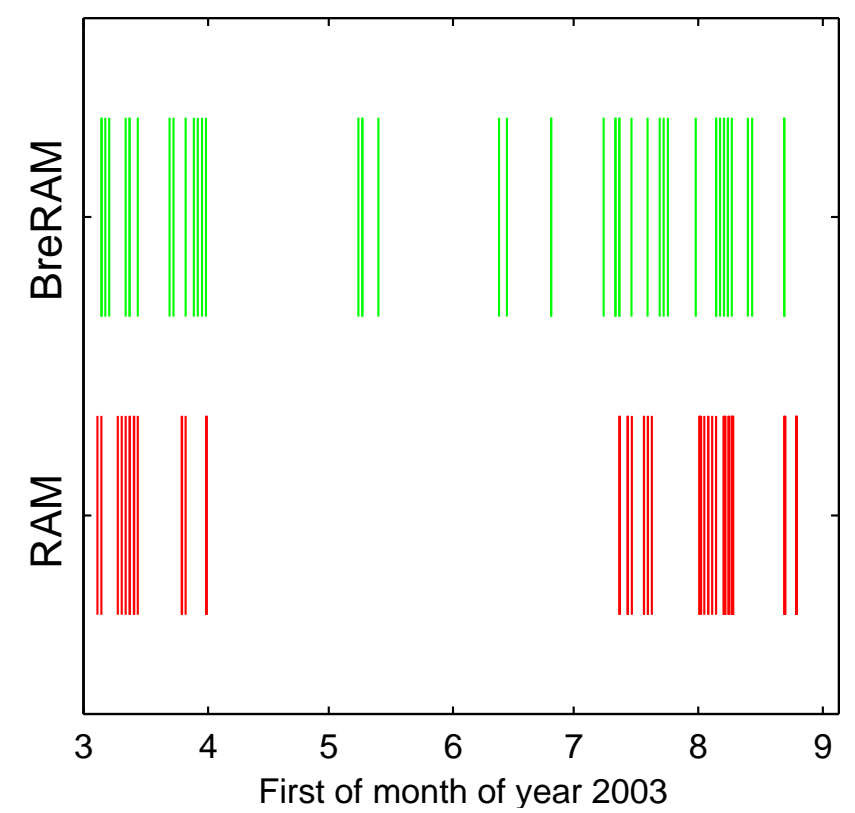

Fig. 4. The distribution of the coincidences from March to August 2003. ENVISAT covers the earth every 3 days. Due to a failure in a ground station not all data could be retrieved from the satellite. There are gaps in the time series of the ground based instruments due to maintenance or bad meteorological conditions.

\subsection{Simulating one retrieval with another}

Again it is assumed that both profiles $\hat{\boldsymbol{x}}_{1}$ and $\hat{\boldsymbol{x}}_{2}$ are with respect to the same a priori profile $\boldsymbol{x}_{\boldsymbol{c}}$. Retrieval 1 is simulated using retrieval 2 by:

$\hat{\boldsymbol{x}}_{12}=\boldsymbol{x}_{c}+\mathbf{A}_{1}\left(\hat{\boldsymbol{x}}_{2}-\boldsymbol{x}_{c}\right)$

The difference of the profiles is

$\boldsymbol{\delta}_{12}=\boldsymbol{x}_{1}-\boldsymbol{x}_{12}=\left(\mathbf{A}_{1}-\mathbf{A}_{1} \mathbf{A}_{2}\right)\left(\boldsymbol{x}_{\text {True }}-\boldsymbol{x}_{c}\right)+\boldsymbol{\epsilon}_{1}-\boldsymbol{\epsilon}_{2}$

and the covariance of the difference is found by

$\mathbf{S}_{12}=\left(\mathbf{A}_{1}-\mathbf{A}_{1} \mathbf{A}_{2}\right) \mathbf{S}_{c}\left(\mathbf{A}_{1}-\mathbf{A}_{1} \mathbf{A}_{2}\right)^{T}+\mathbf{S}_{1}+\mathbf{A}_{1} \mathbf{S}_{2} \mathbf{A}_{1}^{T}$.

The expected variances of the ground-based retrievals simulated by the SCIAMACHY retrieval are shown in Fig. 3. For the intercomparison using simulated retrievals the expected standard deviation is smaller than for direct intercomparison. In fact it is only a little larger than the expected standard deviation for the BreRAM profile. The cause for this effect is the much better altitude resolution of the SCIAMACHY instrument. This means the gradients and hence the variations in the SCIAMACHY-profile can be larger than those in the BreRAM- and RAM-profiles without changing the "mean"profile. The expected error of the direct comparison (Eq. 9) has to account for this.

\section{Results}

4.1 Assumptions and procedure of the comparison

The most important difference of the SCIAMACHY instrument on the one hand and all other, ground-based, instruments on the other hand is the measuring geometry. While SCIAMACHY measurements are integrated over a large area (the SCIAMACHY pixel is about $1000 \mathrm{~km} \times 400 \mathrm{~km}$ ) the ground-based instruments integrate over an area of less than $100 \mathrm{~km} \times 100 \mathrm{~km}$ depending on the viewing angle.

Measurements are compared if the location of the groundbased instrument is within the SCIAMACHY pixel plus $500 \mathrm{~km}$. The overflights of the ENVISAT satellite are at 10 o'clock local time. Because $\mathrm{O}_{3}$ starts to exhibit a daynight change above an altitude of approximately $40 \mathrm{~km}$, the time difference is required to be less than $2 \mathrm{~h}$. Care has been taken in order to measure comparable air masses. There are several constraints to consider:

1. The mean of the total ozone columns $m_{S}$ within the SCIAMACHY pixel is compared to the total ozone column above the location of the radiometer $m_{G}$. Let the difference of the mean $m_{0}$ be defined by:

$m_{0}=\frac{m_{S}-m_{G}}{m_{G}}$.

A publication by Lamsal et al. (2003) indicates that the ozone profile for a given latitude and season approximately scales with the total $\mathrm{O}_{3}$-column. Lamsal et al. (2003) used a binning of $30 \mathrm{DU}$ which corresponds to ca $8-10 \%$ of the ozone column typically observed. The profiles shown by Lamsal et.al. vary less than ca. 5\% per bin. Because this is less than the error expected by the standard deviation of the comparison (see green line in Fig. 3) a value of 5\% for $m_{0}$ is a reasonable compromise between the number of coincidences and quality of the comparison. The variation of the total ozone column has also been checked. There were no matches, however, where the variance of the total ozone column was larger than a few percent. The total ozone columns were measured by the TOMS instrument on the EP satellite but will be provided by SCIAMACHY itself in future.

2. The potential vorticity (PV) on the $475 \mathrm{~K}$ isentrope is calculated in order to ensure that the measurements are completely either inside or outside the polar vortex. The same PV of either larger than $40 \mathrm{PVU}$ (potential vorticity units; inside the vortex) or smaller than $30 \mathrm{PVU}$ (outside the vortex) is required for both measurement areas. All coincident measurements in 2003 above Ny Ålesund were outside the vortex. ${ }^{1}$

\footnotetext{
${ }^{1}$ No match has been excluded or was near the vortex boundary because of this criterion. Therefore, no other criterion for the vortex has been used.
} 


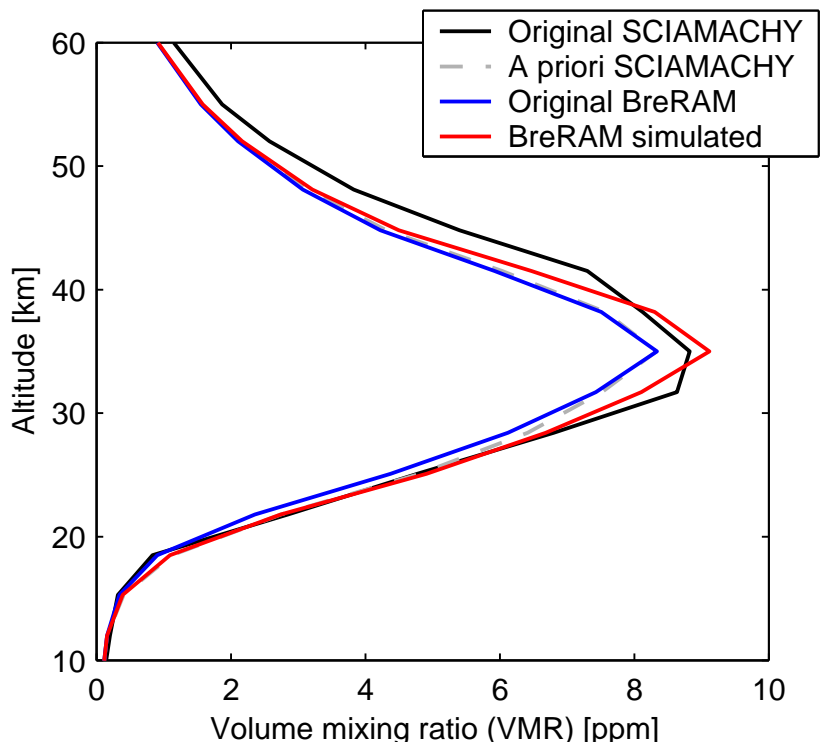

Fig. 5. Example profiles retrieved by SCIAMACHY (black), the BreRAM retrieval simulated using the same SCIAMACHY profile (red) and the BreRAM vmr profile (blue) of Ozone the thin grey line is the a priori profile $x_{c}$ on the 8th of August 2003. The SCIAMACHY a priori is a zonal and montly mean. The retrievals of the BreRAM are therefore expected to be close to the a priori.

All coincidences took place between March and August 2003 (see Fig. 4).

The retrieved ozone profiles have been processed as follows:

1. vmrs are calculated from the concentration profiles provided by SCIAMACHY using ECMWF ERA-40 temperature and pressure profiles,

2. the profiles are transformed to a common a priori (taken from the climatology used by the SCIAMACHY retrieval) $\boldsymbol{x}_{c}$ and

3. the retrievals of the ground-based instruments are simulated using the SCIAMACHY retrieved profiles by

$\hat{\boldsymbol{x}}_{S I M}=\boldsymbol{x}_{c}+\mathbf{A}_{G}\left(\hat{\boldsymbol{x}}_{S}-\boldsymbol{x}_{c}\right)$,

where the index $G$ denotes a quantity derived from the measurements of one of the ground-based instruments BreRAM and RAM. The index $S$ denotes a quantity derived from the SCIAMACHY measurement. Note: Simulating the SCIAMACHY retrieval using RAMprofiles will not lead to a significant reduction of $\mathbf{S}_{12}$. The reason is similar to the one given at the end of section 3.2 can be invoked.

In this work profiles are compared on a profile by profile basis. The relative mean deviation $\Delta_{x}$ of $N$ profiles is

$\Delta_{x}=\sum_{i=1}^{N} \frac{2 *\left(\hat{x}_{G}^{i}-\hat{x}_{S I M}^{i}\right)}{\hat{x}_{G}^{i}+\hat{x}_{S I M}^{i}}$.

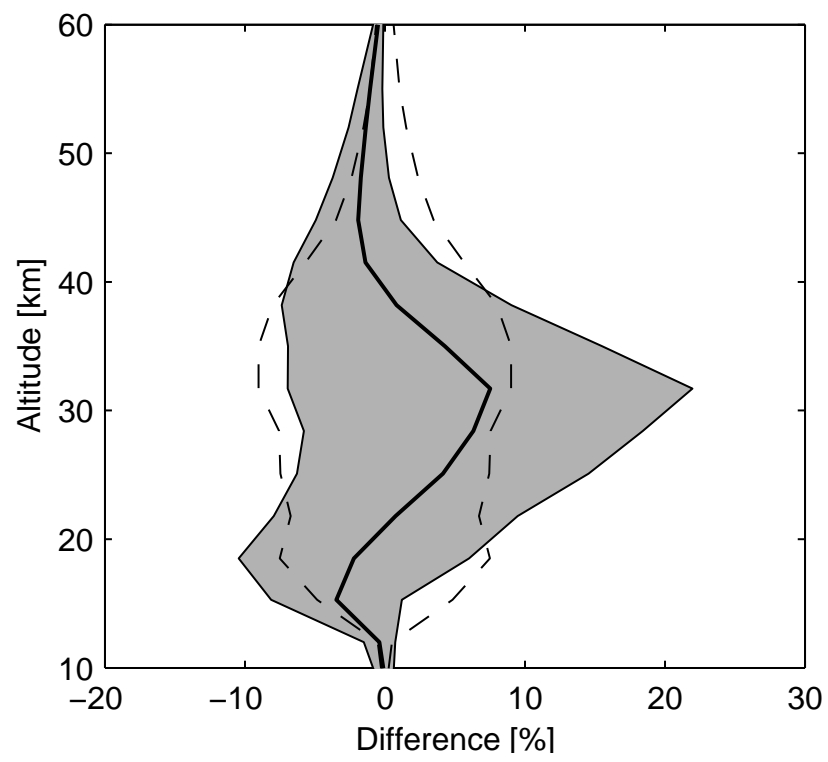

Fig. 6. Relative mean difference $\Delta_{x}$ (see Formula 15) BreRAM to SCIAMACHY. The shaded area is the standard deviation of $\Delta_{x}$ and the dashed line denotes the standard deviation of the comparison $\mathbf{S}_{12}$.

In a second comparison it has been examined if the retrieved maximum of the $\mathrm{O}_{3}$-vmr is at the same altitude in the compared retrievals. This test is very sensitive to shifts in the retrieved profile which may occur in the SCIAMACHY retrieval (see section 4.2 for further explanation).

\subsection{Comparison results SCIAMACHY - BreRAM}

Between March 2003 and August 200364 collocations were found. After checking for the total $\mathrm{O}_{3}$ columns 19 coincident measurements were discarded. ${ }^{2}$ The profiles in Fig. 5 show a very good agreement of the shapes of the retrieved $\mathrm{O}_{3}$ profiles. The relative mean of the difference (Fig. 6) also shows a good agreement between the BreRAM and the SCIAMACHY profile. The relative mean deviation is smaller than $10 \%$ and is within the expected standard deviation $\mathbf{S}_{12}$ of the comparison. The altitude of the maximum $\mathrm{vmr}$ is found in $75 \%$ of the retrievals (see Fig. 7). However, the SCIAMACHY retrieval tends to underestimate the vmr compared with the BreRAM apart from the range 15-20 km.

It must be mentioned that the SCIAMACHY limb observations suffered from inaccurate pointing for all the measurements used in this study. Tangent height offsets of up to $3 \mathrm{~km}$ were detected. The limb pointing is very accurate immediately after the daily updates of the on-board orbit model. After these updates, the pointing slowly deviates from nominal

\footnotetext{
${ }^{2}$ Increasing the number of coincident measurements by trajectory hunting methods (e.g. Danilin et al., 2002) is not possible because of the altitude resolution of the ground-based instruments (see also Langer, 1999).
} 


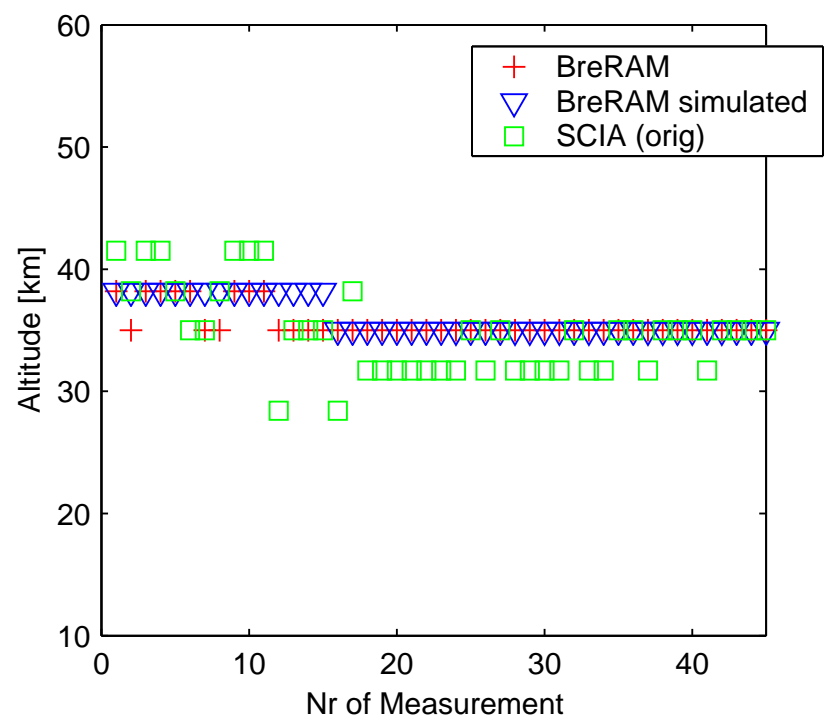

Fig. 7. Altitudes of the maximum of the retrieved volume mixing ratio.

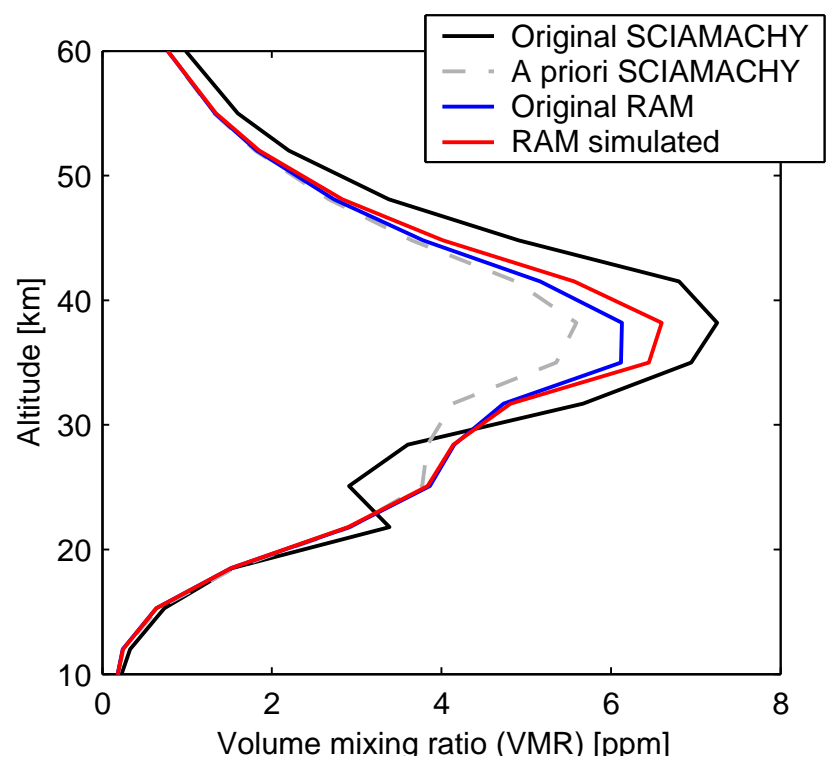

Fig. 8. Example profiles retrieved by SCIAMACHY (black), the RAM-retrieval simulated using the same SCIMACHY profile (red) and the RAM vmr profile (blue) of Ozone, the thin grey line is the a priori profile $x_{c}$, on the 9th of August 2003. The SCIAMACHY a priori is a zonal and montly mean. The retrievals of the RAM are therefore expected to be close to the a priori.

pointing until the next update occurs. As a first order pointing correction a constant tangent height offset of $1.5 \mathrm{~km}$ was subtracted from the tangent heights prior to the inversion procedure. This implies, that tangent height offsets of up to $1.5 \mathrm{~km}$ have to be expected. These offsets basically lead to a retrieved $\mathrm{O}_{3}$ profile that is shifted by the tangent height error (von Savigny et al., 2004).

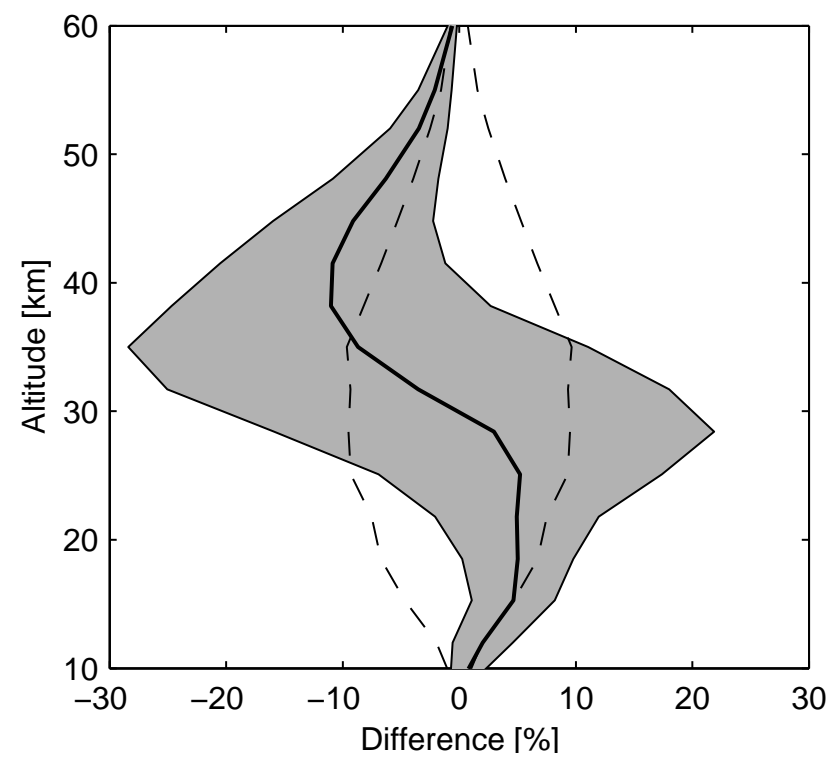

Fig. 9. Relative mean difference $\Delta_{x}$ (see Formula 15) RAM to SCIAMACHY. The shaded area is the standard deviation of $\Delta_{x}$ and the dashed line denotes the standard deviation of the comparison $\mathbf{S}_{12}$.

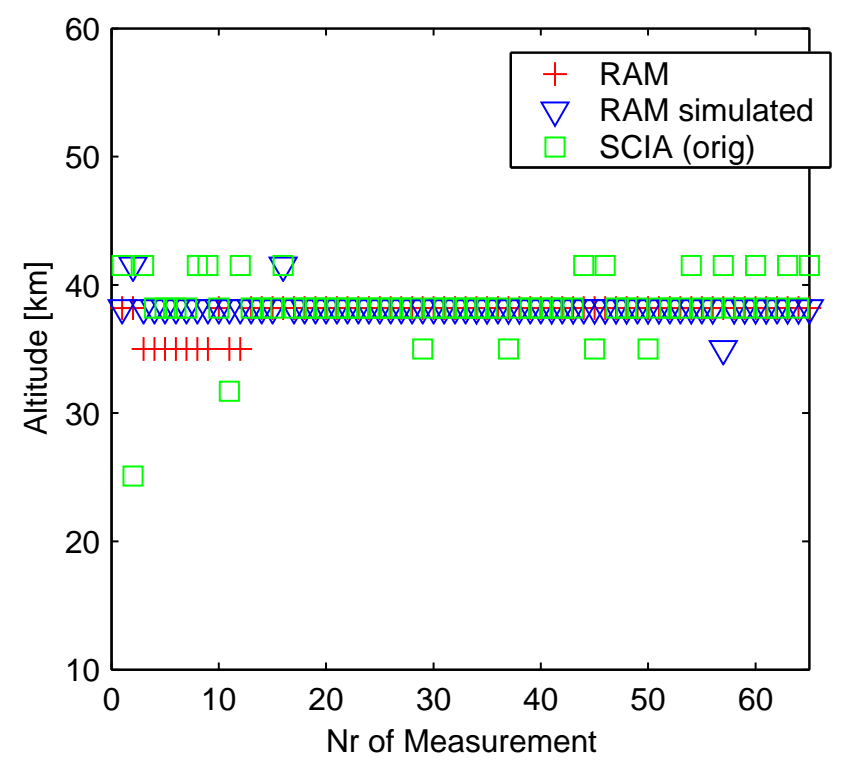

Fig. 10. Altitudes of the maximum of the retrieved volume mixing ratio.

\subsection{Comparison results SCIAMACHY-RAM}

Between March 2003 and August 200395 collocations have been found. By applying the selection criteria for the total $\mathrm{O}_{3}$ column 30 coincident measurements were discarded.

The profiles in Fig. 8 show very good agreement in the shape of the profiles and the vmr retrieved. The relative mean deviation is smaller than $15 \%$ (see Fig. 9), i.e. somewhat larger than for the SCIAMACHY-BreRAM 
comparison. Above $35 \mathrm{~km}$ SCIAMACHY retrieves vmr values higher than the RAM. The altitude of the maximum vmr is found in most of the cases (see Fig. 10).

\section{Conclusions}

Comparisons of the high altitude resolution remote sounder SCIAMACHY with two ground-based millimeter-wave sounders and a ground-based FTIR sounder are shown.

The comparability is ensured by constraints on the SCIAMACHY pixel in terms of the total ozone column and the potential vorticity. The profiles retrieved from the SCIAMACHY measurements and the millimeter wave measurements agree in shape as well as in altitude of the maximum vmr. The differences in the retrieved vmr are in the range of the expected standard deviation of the comparison except above $35 \mathrm{~km}$ altitude in case of the RAM.

The statistical basis for the intercomparison of this study is still quite small. However, the statistical basis is expected to improve with the lifetime of the SCIAMACHY instrument. Newer millimeter wave instruments like RAMAS on Greenland (Golchert et al., 2004) will contribute more coincident measurements and improve the quality of the comparison because of their better altitude resolution (expected $10 \mathrm{~km}$ over a range of 20 to $45 \mathrm{~km}$ ).

Acknowledgements. We would like to thank the Alfred Wegener Institute Bremerhaven for providing the infrastructure to carry out millimeter-wave measurements at Ny Ålesund, Spitsbergen. We also thank the various technicians and other personnel at the research stations in Ny Ålesund and Bremen for their support.

For providing the data of total $\mathrm{O}_{3}$ columns we thank the NASA Goddard Space Flight Center.

This work has been funded by the DLR.

Edited by: U. Platt

\section{References}

Barret, B., Mazière, M. D., and Demoulin, P.: Retrieval and characterization of ozone profiles from solar infrared spectra at the Jungfraujoch, J. Geophys. Res., 107(D24), 4788, doi:10.1029/2001JD001298, 2002.

Bovensmann, H., Burrows, J. P., Buchwitz, M., Frerick, J., Noël, S., Rozanov, V. V., Chance, K. V., and Goede, A. P. G.: SCIAMACHY: Mission Objectives and Measurement Modes, J. Atmos. Sci., 56, 127-150, 1999.

Brown, L., Gunson, M., Toth, R., Irion, F., Rinsland, C., and Goldman, A.: The 1995 atmospheric trace molecule spectroscopy (ATMOS) linelist, Appl. Opt., 35, 2828-2848, 1996.

Danilin, M., Ko, M., Froidevaux, L., Santee, M., Lyjak, L., Bevilacqua, R., Zawodny, J., Sasano, Y., Irie, H., Kondo, Y., Russel III, J., Scott, C., and Read, W.: Trajectory hunting as an effective technique to validate multiplatform measurements: Analysis of the MLS, HALOE, SAGE-II, ILAS, and POAM data
October-November 1996, J. Geophys. Res., 107(D20), 4420, doi:10.1029/2001JD002012, 2002.

Farman, J., Gardiner, B., and Shanklin, J.: Large losses of total ozone in Antarctica reveal seasonal $\mathrm{ClOx} / \mathrm{NOx}$ interaction, Nature, 315, 207-210, 1985.

Flittner, D. E., Bhartia, P. K., and Herman, B. M.: $\mathrm{O}_{3}$ profiles retrieved from limb scatter measurements, Geophys. Res. Lett., 27, 2601-2604, doi:10.1029/1999GL011343, 2000.

Golchert, S., Buschmann, N., Kleindienst, A., Palm, M., Künzi, K., Notholt, J., de la Nöe, J., Schneider, N., Sorensen, H., Gross, A., and Chipperfield, M.: Comissioning of the new Ground-Based Microwave Radiometer RAMAS at Summit, Greenland, Poster presentation at the Microrad04 conference in Rom, Italy, http://www.ram.uni-bremen.de/pdf_poster/poster rome-microrad04_ramas.pdf, 2004.

Kaiser, J. W. and Burrows, J. P.: Fast weighting functions for retrievals from limb scattering measurements, JQSRT, 77, 273283, 2003.

Lamsal, L., Weber, M., Tellmann, S., and Burrows, J.: Ozone column classified climatology of ozone and temperature profiles based on ozonesonde and satellite data, J. Geophys. Res., 109, D20304, doi:10.1029/2004JD004680, 2004.

Langer, J.: Measurements of Arctic stratospheric ozone: Comparison of ozone-measurements at Ny-Ålesund, Spitsbergen, in 1997 and 1998, PhD thesis, University of Bremen, in German, 1999.

McPeters, R. D., Janz, S. J., Hilsenrath, E., Brown, T. L., Flittner, D., and Heath, D.: The retrieval of $\mathrm{O}_{3}$ profiles from limb scatter measurements: Results from the Shuttle Ozone Limb Sounding Experiment, Geophys. Res. Lett., 27(17), 2597-2600, doi:10.1029/1999GL011342, 2000.

Notholt, J.: The moon as light source for FTIR measurements of stratospheric trace gases during the polar night: Application for HNO3 in the Arctic, J. Geophys. Res., 99, 3607-3614, 1994.

Notholt, J. and Schrems, O.: Ground-based FTIR measurements of vertical column densities of several trace gases above Spitzbergen, Geophys. Res. Lett., 21, 1355-1358, 1994.

Pougatchev, N. S., Connor, B. J., and Rinsland, C. P.: Validation of ozone profile retrievals from ground-based solar spectra, Geophys. Res. Lett., 23(13), 1637-1640, 1996.

Rex, M., Salawitch, R., von der Gathen, J. P., Harris, N., Chipperfield, M., and Naujokat, B.: Arctic ozone loss and climate change, Geophys. Res. Lett., 31, L04 116, doi:10.1029/2003GL018844, 2004.

Rinsland, C. P., Jones, N. B., Connor, B. J., et al.: Northern and southern hemisphere ground-based infrared spectroscopic measurements of tropospheric carbon monoxide and ethane, J. Geophys. Res., 103(D21), 28 197-28 217, 1998.

Rodgers, C. D.: Inverse methods for atmospheric sounding, vol. 2 of Series on Atmospheric, Oceanic and Planetary Physics, World Scientific, 2000

Rodgers, C. D. and Connor, B. J.: Intercomparison of remote sounding instruments, J. Geophys. Res., 108, doi:10.1029/2002JD002299, 2003.

Toon, G. C., Blavier, F.-F., Sen, B., Salawitch, R. I., Ostermann, G. B., Notholt, J., Rex, M., McElroy, G. T., and Russell III, M.: Ground-based observations of Arctic O3 loss during spring and summer 1997, J. Geophys. Res., 104, 26 497-26 510, 1999. 
von Savigny, C., Haley, C. S., Sioris, C. E., et al.: Stratospheric Ozone Profiles retrieved from Limb Scattered Sunlight Radiance Spectra Measured by the OSIRIS Instrument on the Odin Satellite, Geophys. Res. Lett., 30, doi:10.1029/2002GL016401, 2003. von Savigny, C., Rozanov, A., Bovensmann, K.-U., Noël, S., Rozanov, V. V., Sinnhuber, B. M., Weber, M., Burrows, J. P., and Kaiser, J. W.: The ozone hole break up in September 2002 as seen by SCIAMACHY on ENVISAT, J. Atmos. Sci., 62(3), 721-734, 2005.
Wohltmann, I.: Ozone depletion, chlorine activation and water vapour observed in Spitsbergen, $\mathrm{PhD}$ thesis, Universität Bremen, 2002. 